\title{
Effect of solar flare on the equatorial electrojet in eastern Brazil region
}

\author{
R G Rastogi ${ }^{1}$, P Janardhan $^{1}$, H Chandra $^{1, *}$, N B Trivedi $^{2}$ and Vidal Erick ${ }^{3}$ \\ ${ }^{1}$ Physical Research Laboratory, Ahmedabad 380 009, India. \\ ${ }^{2}$ National Institute for Space Research - INPE, Sao Jose dos Campos, SP 12227-010, Brazil. \\ ${ }^{3}$ Instituto Geofisico del Peru, Huancayo, Peru. \\ *Corresponding author. e-mail: hchandra@prl.res.in
}

MS received 15 April 2016; revised 9 January 2017; accepted 6 February 2017; published online 7 June 2017

The effect of solar flare, sudden commencement of magnetic storm and of the disturbances ring current on the equatorial electrojet in the Eastern Brazil region, where the ground magnetic declination is as large as $20^{\circ} \mathrm{W}$ is studied based on geomagnetic data with one minute resolution from Bacabal during November-December 1990. It is shown that the mean diurnal vector of the horizontal field was aligned along $2^{\circ} \mathrm{E}$ of north at Huancayo and $30^{\circ} \mathrm{W}$ of north at Bacabal during the month of December 1990 . Number of solar flares that occurred on 30 December 1990 indicated the direction of solar flare related $\Delta H$ vector to be aligned along $5^{\circ} \mathrm{E}$ of north at Huancayo and $28^{\circ} \mathrm{W}$ of north at Bacabal. This is expected as the solar flare effects are due to the enhanced conductivity in the ionosphere. The SC at $2230 \mathrm{UT}$ on 26 November 1990 produced a positive impulse in $\Delta X$ and negative impulse in $\Delta Y$ at Bacabal with $\Delta H$ vector aligned along $27^{\circ} \mathrm{W}$ of north. At Huancayo the $\Delta H$ vector associated with $\mathrm{SC}$ is aligned along $8^{\circ} \mathrm{E}$ of north, few degrees east to the alignment of the diurnal vector of $H$. The magnetic storm that followed the SC had a minimum Dst index of $-150 \mathrm{nT}$. The corresponding storm time disturbance in $\Delta X$ at Huancayo as well as at Bacabal were about $-250 \mathrm{nT}$ but $\Delta Y$ at Bacabal was about $+70 \mathrm{nT}$ and very small at Huancayo, that give the alignment of the $\mathrm{H}$ vector due to ring current about $16^{\circ} \mathrm{W}$ of north at Bacabal and almost along $\mathrm{N}-\mathrm{S}$ at Huancayo. Thus alignment of the $\Delta H$ vector due to ring current at Bacabal is $14^{\circ} \mathrm{E}$ of the mean direction of $\Delta H$ vector during December 1990 . This is consistent with the direction of ring current dependent on the dipole declination at the ring current altitude which is about $5^{\circ} \mathrm{W}$ of north over Bacabal and the deviation of declination due to the ring current during disturbed period given by the angle $(\psi-D)$.

Keywords. Solar flare; equatorial electrojet.

\section{Introduction}

Chapman (1919) first derived the ionospheric current system based on northward $(X)$ and eastward $(Y)$ components of magnetic field at 21 observatories around the world. The current system derived, consisted of two loops in the sunlit hemisphere, centred at $1100 \mathrm{hr}$ local time and $40^{\circ} \mathrm{N}$ and $40^{\circ} \mathrm{S}$ latitudes. The northern loop was anticlockwise and the southern loop was clockwise, spherical. Harmonic analyses were performed of the data from large number of observatories established during the IGY period to derive the ionospheric current system. All these analyses used only the $\mathrm{H}$ field and assumed that the potential of the field depends on the geographic 
latitude and local time (Matsushita and Maeda 1965).

Parkinson (1971) used both the X and Y fields at about 50 observatories. Some terms depending on longitude as well as local time were included. The current pattern was found to be influenced by the asymmetry of the main field and the contours lines of $H$ field for low latitudes were not parallel to the equator and were very much inclined in the region between South America and West Africa.

Riggotti et al. (1999) described the analyses of the data from an array of 29 vector magnetometers which operated in N-NE Brazil from November 1990 to March 1991. They derived a simple model of an equivalent current distribution for the $S q$ and equatorial electrojet (EEJ). Rastogi and Trivedi (2009) analyzed the data of $X, Y$ and $Z$ components of the magnetic field at stations in the Brazilian array. They showed that the variation of $\mathrm{X}$ showed a major maximum around 1200 LT. The daily variation of $\Delta Y$ showed a strong minimum around noon at all stations. The direction of the deviation in the total horizontal field $(\Delta H)$ with respect to the geographic meridian $(\theta)$ was calculated using the relation

$$
\theta=\arctan (\Delta Y / \Delta X)
$$

and measured east of geographic north. The $\Delta H$ vector deduced from $\Delta Y$ and $\Delta X$ was aligned along a direction about $25^{\circ} \mathrm{W}$ of north. Thus the equatorial electrojet currents are inclined to the geographic east by $25^{\circ}$ towards north at the centre of the EEJ belt in this region. The centre of EEJ was found to be near $1.0^{\circ} \mathrm{S}$ dip latitude. These anomalies were suggested to be due to the abnormal distribution of the main magnetic field in the region. Rastogi et al. (2013) compared the characteristics of EEJ at Itinga in Brazil where D was $19.3^{\circ} \mathrm{W}$ and at Huancayo in Peru, where $\mathrm{D}$ was $1.0^{\circ} \mathrm{E}$. The mean value of the diurnal $\mathrm{H}$ field vector was inclined about $20^{\circ} \mathrm{W}$ of north at Itinga and about $1^{\circ} \mathrm{E}$ of north at Huancayo. However, the hourly values for Itinga varied from about $6^{\circ} \mathrm{W}$ of north in the morning to $35^{\circ} \mathrm{W}$ of north in the afternoon. Day to day variations of $H$ field at Huancayo and Itinga were highly correlated but there was no correlation $(<0.2)$ in the daytime values of $\Delta Y$ field at the two stations. Thus, the anomaly of electrojet current direction was characteristic of the east Brazil region.

Olson (1970) suggested that the magnetopause, neutral sheet and ring current make a measurable contribution to the Earth's surface magnetic field besides the average $S q$ field. Sarabhai and Nair (1971) suggested that the $\Delta H$, the daily variation of the horizontal component $H$ at a low latitude station is caused by mainly the dynamo current at the ionospheric E region but are affected by the surface current at the magnetopause, the tail current, eccentric and partial ring current in the magnetosphere.

The enhancement of the horizontal component $(H)$ of the geomagnetic field due to an X-ray flare event is called a Solar Flare effect (SFE). The maximum enhancement in $H$ value over the pre-flare level indicates the magnitude, SFE $(H)$ of an SFE event. The solar flare (magnetic crochet) related current was regarded as an augmentation of the $S q$ current system (Chapman 1961) in the past. Oshio et al. (1967) studied the solar flare effect on the geomagnetic field on a global basis and suggested that the seat of the ionospheric current is little lower than that of the $S q$ current system. McNish (1937) showed that the solar flare induced impulses in $H$ field at low latitudes are aligned with the normal $\Delta H$ at the time of flare. Forbush and Casaverde (1961) showed that the enhancement of SFE in $H$ over the dip equator in Peru varied in a manner similar to the $S q(H)$ variation in equatorial latitudes. Rastogi (2001a, b) studied the SFE in $\Delta H$, $\Delta Y$ and $\Delta Z$ at Trivandrum, close to the magnetic equator and Annamalainagar, a station at the edge of the equatorial electrojet in the Indian region for the period 1957-1982. It was shown that the SFE in $\Delta H$ at Trivandrum was positive during daytime with a broad maximum just before noon but the SFE in $\Delta Y$ was positive in the forenoon and negative in the afternoon consistent with the effects expected of a normal $S q$ current. The mean hourly values of the SFE in $\Delta Y$ were $2 \mathrm{nT}$ or smaller. For Annamalainagar, the amplitude of SFE in $\Delta H$ was positive during daytime with peak around $0930 \mathrm{hr}$. SFE in $\Delta Y$ was positive in the morning hours (06-08 hr) and negative during day time with minimum around noon similar to the variation of $\Delta Y$. There was no linear dependence of the amplitude of SFE in $\Delta Y$ on the amplitude of SFE in $\Delta H$ at Annamalainagar. Rastogi (2003) studied SFE in the geomagnetic components $\Delta H, \Delta Y$ and $\Delta Z$ at Huancayo for the period 1957-1977 and showed the daily variations in conformity with the daily variations of the $\Delta H, \Delta Y$ and $\Delta Z$. Further the SFE $\Delta Y$ was shown to increase linearly with the increase of SFE $\Delta H$ at Huancayo. It must be pointed that the amplitude of the SFE in $\Delta Y$ at Huancayo is 
Table 1. Coordinates, geomagnetic parameters at Huancayo and Bacabal for December 1990.

\begin{tabular}{lcc}
\hline Station name & Huancayo & Bacabal \\
\hline Station code & HUA & BAC \\
Geog. latitude (deg) & $12.0 \mathrm{~S}$ & $4.2 \mathrm{~S}$ \\
Geog. longitude (deg) & $75.3 \mathrm{~W}$ & $44.8 \mathrm{~W}$ \\
Northward field, $X$ (nT) & 26,620 & 25,329 \\
Eastward field, $Y(\mathrm{nT})$ & 452 & -9234 \\
Vertical field, $Z(\mathrm{nT})$ & 748 & 956 \\
Horizontal field, $H(\mathrm{nT})$ & 26,624 & 27,007 \\
Dip latitude (deg) & 0.8 & -0.8 \\
Declination (ionosphere) D (deg) & $1.0 \mathrm{E}$ & $20.0 \mathrm{~W}$ \\
\hline
\end{tabular}

much larger at Huancayo as compared to that at Trivandrum with mean hourly values of up to 12 $\mathrm{nT}$.

It was felt important to check the direction of ionospheric current in the region of Eastern Brazil using the solar flare effects in $\Delta X$ and $\Delta Y$ fields. Fortunately, there were a number of solar flares on 30 December 1990 and most of these occurred during daytime in Latin American region. In this paper, we have studied the SFE in $\Delta X$ and $\Delta Y$ at Bacabal and Huancayo. The coordinates of the two stations are given in table 1. It is to be noted that the dip latitude at Huancayo was $+0.8^{\circ}$ and at Bacabal $-0.8^{\circ}$, but the declination at Huancayo was $1.0^{\circ} \mathrm{E}$ while at Bacabal it was $20^{\circ} \mathrm{W}$. Thus, the horizontal magnetic field $\mathrm{H}$ was deviated to only $1^{\circ} \mathrm{E}$ of north at Huancayo but $20^{\circ} \mathrm{W}$ of north at Bacabal.

\section{Results}

Plots of the hourly mean $H$ vectors averaged over December 1990 for Huancayo and Bacabal are shown in figure 1 from the $\Delta X$ and $\Delta Y$ values. Dotted lines show the direction in the figure. The daytime vectors at Huancayo are almost aligned along a straight line pointing to a direction of $2^{\circ} \mathrm{E}$ of north. For Bacabal daytime values lie along an elongated ellipse with individual values ranging from $20^{\circ} \mathrm{W}$ of north to more than $35^{\circ} \mathrm{W}$ of north and the major axis pointing to $30^{\circ} \mathrm{W}$ of north. The alignment of the $\Delta H$ vector is almost along the declination at Huancayo but about $10^{\circ} \mathrm{W}$ of the declination at Bacabal. Solar charged particle precipitation and meridional currents have been suggested for the anomalies seen in east Brazilian sector (Rastogi and Trivedi 2009). Further there are changes in the center of electrojet with local time that can lead to changes in the direction of current (Rastogi et al. 2010).

Figure 2 shows the intensity of solar x-ray radiations in the two wave-length bands of 5-30 $\mathrm{nm}$ (shown by red line) and 10-80 nm (blue line) measured from GOES-6 satellite on 30 December, 1990 indicating a large number of solar flares that occurred on that day. It may be noted that the solar flare at 1027 UT corresponded to 1327 LT for Huancayo and 1527 LT for Bacabal. Similarly, the local times of the largest flare at 1515 UT were $1015 \mathrm{hr}$ at Huancayo and $1215 \mathrm{hr}$ at Bacabal.

Figure 3 shows the $\Delta H$ and $\Delta Y$ variations at Huancayo on 30 December, 1990. It may be noted that $\Delta H$ at Huancayo will be almost equal to $\Delta X$ as the declination value is close to zero. Figure 4 shows the $\Delta X$ and $\Delta Y$ magnetograms at Bacabal on 30 December, 1990. The amplitudes of $\Delta X$ and $\Delta Y$ values in response to individual solar flares at Huancayo and Bacabal on 30 December 1996 are given in table 2. It can be seen that the $\mathrm{SFE}$ in $\Delta Y$ at Huancayo were small in the range of $3-8$ $\mathrm{nT}$ compared to the SFE in $\Delta X$ with values in the range of $30-78 \mathrm{nT}$. The $\mathrm{SFE}$ in $\Delta H$ are aligned in the range of $5^{\circ}-6^{\circ} \mathrm{E}$ of north with the mean direction of SFE vector about $5.4^{\circ} \mathrm{E}$. At Bacabal the $\mathrm{SFE}$ in $\Delta Y$ were in the range of -3 to $-24 \mathrm{nT}$ and the corresponding $\mathrm{SFE}$ in $\Delta X$ were in the range of 7-39 nT. The direction of the SFE in $H$ varied from 23 to $32^{\circ} \mathrm{W}$ of north with the mean direction $28.7^{\circ} \mathrm{W}$ of north. Considering the accuracy of the measurements of the geomagnetic field to be $1 \mathrm{nT}$, the error in the computation of the direction of the $H$ vector associated with the solar flare effects are about $1^{\circ}$ at Huancayo and $2^{\circ}$ to $10^{\circ}$ for Bacabal. It may be noted that the mean direction of the $\mathrm{SFE}$ in $\mathrm{H}$ of $28.7^{\circ} \mathrm{W}$ of north is very close to the 

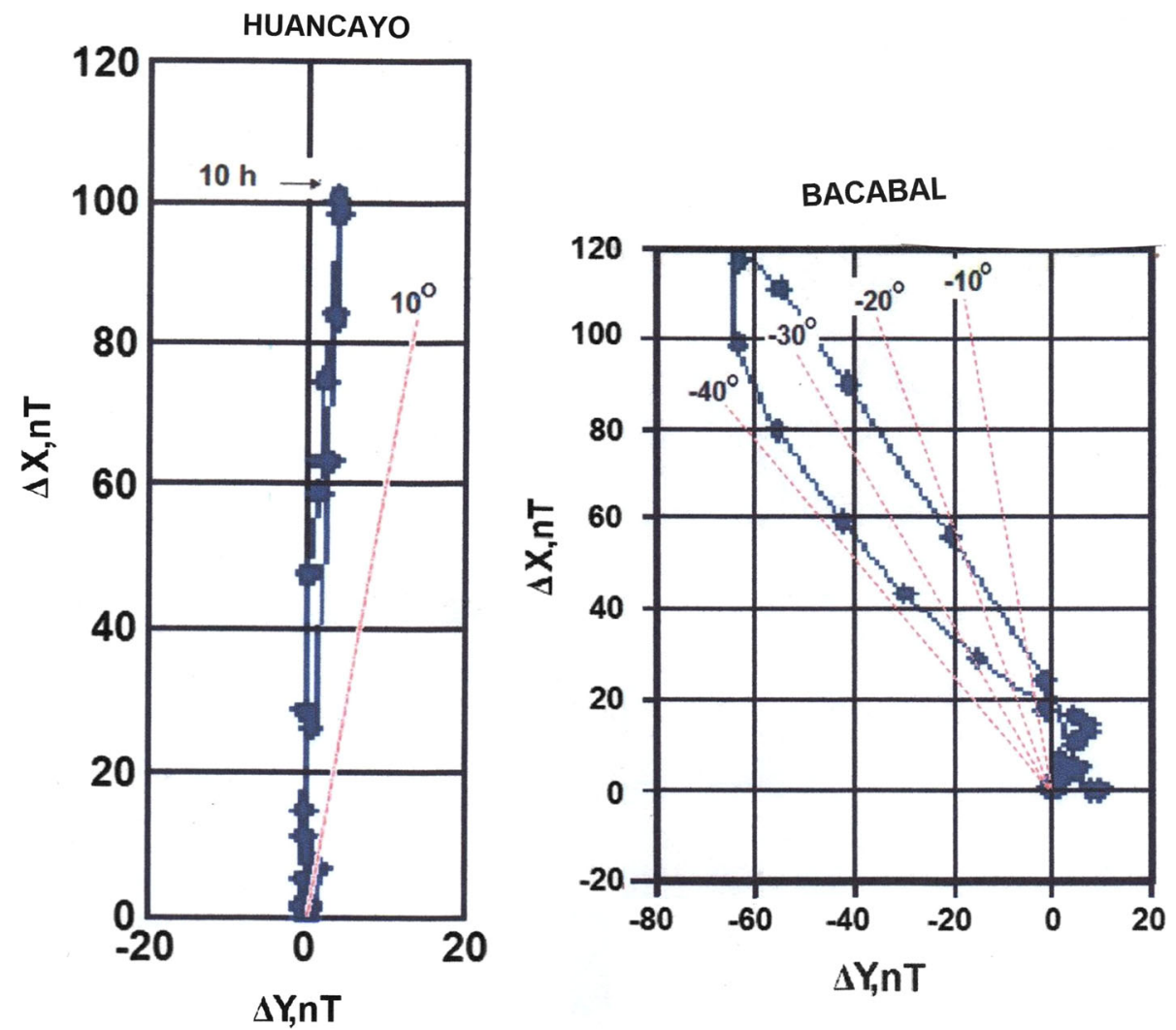

Figure 1. The monthly mean diurnal variation loops of $\Delta X$ and $\Delta Y$ at Huancayo and Bacabal during December 1990 .

Solarx-rays@GOES-6

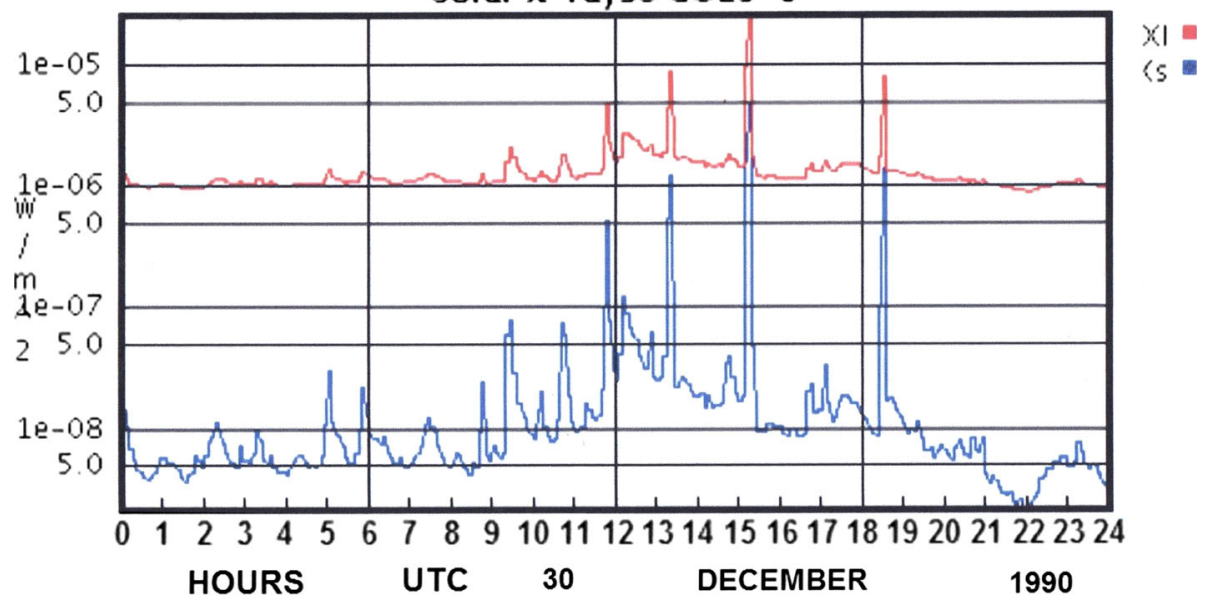

Figure 2. Solar X-ray flare plots on 30 December 1990 from GOES-6 Satellite.

direction of diurnal $\mathrm{H}$ vector at Bacabal $\left(30^{\circ} \mathrm{W}\right.$ of north).

\section{Discussion}

Based on a number of solar flares on 30 December 1990, the direction of solar flare $\Delta H$ vector was observed to be aligned along $5^{\circ} \mathrm{E}$ of north at Huancayo and $28^{\circ} \mathrm{W}$ of north at Bacabal. These are close to the respective alignment of the monthly mean diurnal vectors of $\Delta H$, along $2^{\circ} \mathrm{E}$ of north at Huancayo and $30^{\circ} \mathrm{W}$ of north at Bacabal during the month of December 1990. This is expected as the solar flare effects are due to the sudden enhancements of the conductivity resulting from the enhanced ionization in the $\mathrm{D}$ and lower $\mathrm{E}$ regions of the ionosphere. We have also computed the $\Delta H$ vectors at Bacabal and Huancayo associated with the SC at $2230 \mathrm{UT}$ on 26,1990 . It was 
HUANCAYO

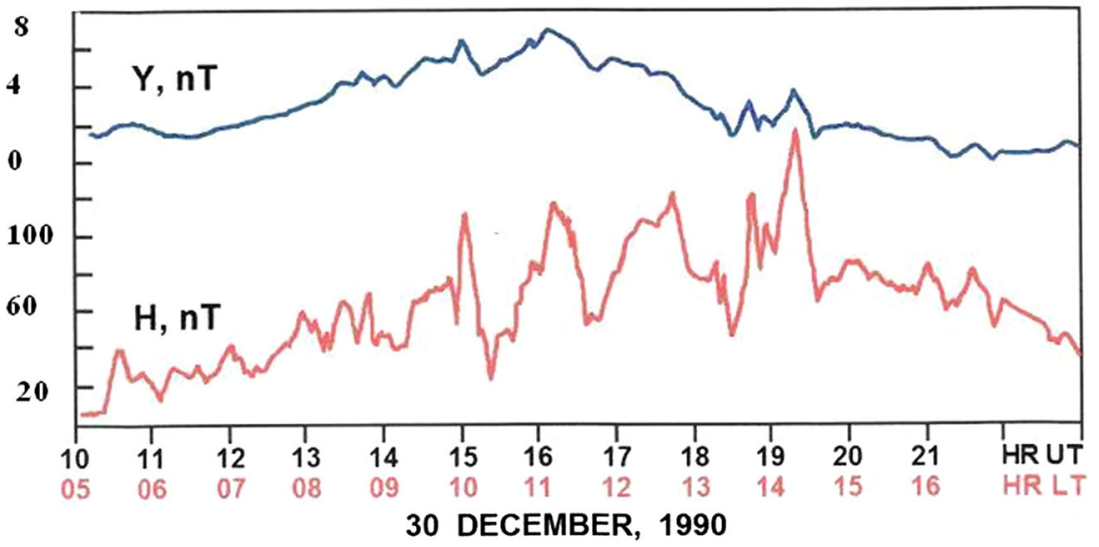

Figure 3. The daily plots of $\Delta H$ and $\Delta Y$ at Huancayo, Peru on 30 December, 1990.

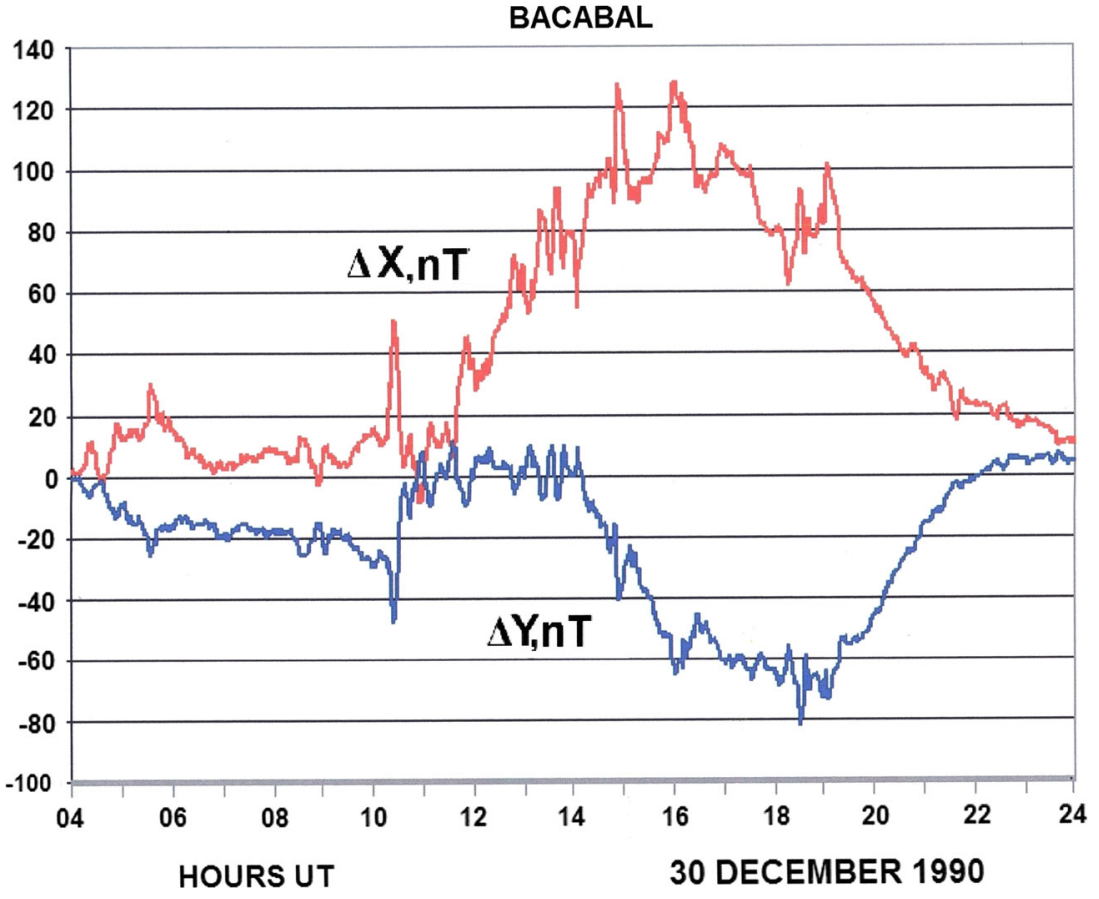

Figure 4. The daily plots of $\Delta X$ and $\Delta Y$ at Bacabal, Brazil on 30 December, 1990.

Table 2. Amplitudes of crochet on 30 December 1990.

\begin{tabular}{lcccccccc}
\hline \multirow{2}{*}{ Time UT } & \multicolumn{3}{c}{ Bacabal } & & \multicolumn{3}{c}{ Huancayo } \\
\cline { 2 - 4 } & $\Delta X(\mathrm{nT})$ & $\Delta Y(\mathrm{nT})$ & $\theta^{\circ} \mathrm{E}$ & & $\Delta X(\mathrm{nT})$ & $\Delta Y(\mathrm{nT})$ & $\theta^{\circ} \mathrm{E}$ \\
\hline 0531 & 12 & -7 & -30.1 & - & - & - \\
0831 & 7 & -3 & -23.3 & - & - & - \\
1017 & 39 & -22 & -29.2 & & 43 & 4 & 5.3 \\
1138 & 34 & -18 & -27.9 & & 43 & 4 & 5.3 \\
1313 & 28 & -14 & -26.5 & & 30 & 3 & 5.7 \\
1515 & 39 & -24 & -31.4 & & 55 & 5 & 5.1 \\
1827 & 19 & -12 & -32.2 & & 78 & 8 & 5.8 \\
Mean & & & -28.7 & & & 5.4 \\
\hline
\end{tabular}


aligned along $29^{\circ} \mathrm{W}$ of north at Bacabal, which is close to the alignment of the monthly mean diurnal vectors of $\Delta H$ at Bacabal. At Huancayo, the $\Delta Y$ associated with the $\mathrm{SC}$ is small and the $\Delta H$ vector was aligned about $8^{\circ} \mathrm{E}$ of $\mathrm{N}$. Considering the error involved of about $2^{\circ}$ in computing, $\Delta H$ vector associated with $\mathrm{SC}$ is few degrees $\mathrm{E}$ to the alignment of the diurnal vector of $H$ at Huancayo. The disturbance field of the $\mathrm{SC}$ is primarily due to two components. The DL component, an abrupt increase of the magnetopause current associated with the sudden compression of the magnetosphere dominates at low latitudes. DP component is dominant in the polar region and extends to lower latitudes due to a polar electric field transmitted along the magnetic lines of force from magnetosphere (Araki 1977). This field is significantly enhanced at the dayside dip equator. High latitude dusk to dawn electric field penetrates to low latitudes. The ionospheric currents due to this electric field will add to the normal ionospheric current. In addition to the magnetopause currents, there are secondary currents like the field-aligned currents, ionospheric current and tail current. The polarity of the IMF-Bz also plays an important role in the response to the solar wind dynamic pressure. Russel et al. (1994) studied the response of low-latitude $H$ component during the passage of interplanetary shocks both during the northward and southward IMF-Bz conditions. They reported the largest SC amplitudes around noon during northward IMF and near midnight during the southward IMF. For the northward IMF magnetopause currents govern principally the amplitude of SC during dayside. Tail currents, which act in the opposite sense to magnetopause currents are also enhanced and have greater effect in the night than in daytime. In case of southward IMF, daytime response to solar wind pressure increases is over $25 \%$ smaller probably because of region 1 current system associated with dayside reconnection, however at night the mid and low-latitude response is much greater and attributed to the triggering of substorms in magnetotail. However, Clauer et al. (2001) reported an event with largest SC amplitude in night-time during a northward turning of IMF. Araki et al. (2006) examined a number of large amplitude SC events observed at Kakioka during the period 1924-1994. Large amplitudes SCs ( $\mathrm{H}$ component larger than $40 \mathrm{nT}$ ) occur more frequently during the night time than the daytime. Three large amplitude SCs (more than $85 \mathrm{nT}$ ) showed largest amplitude near midnight in low latitudes except the dayside equator. Further the case studies for two moderate amplitude SCs events at same UT showed that the nighttime SC amplitude are slightly (considerably) larger than daytime amplitudes when IMF points northward (southward). Diurnal variation of the SC amplitudes was explained by a combination of field-aligned and resultant ionospheric currents produced during the main impulse of SCs.

The magnetic storm following the SC had a minimum Dst index of $-150 \mathrm{nT}$ and the corresponding storm time disturbance in $\Delta X$ at Huancayo and Bacabal were about $250 \mathrm{nT}$. $\Delta Y$ at Bacabal was about $+70 \mathrm{nT}$ and as expected very small at Huancayo. The alignment of the $\mathrm{H}$ vector associated with the ring current is about $16^{\circ} \mathrm{W}$ of north at Bacabal and almost along $\mathrm{N}-\mathrm{S}$ for Huancayo. The alignment of the $\mathrm{H}$ vector due to ring current at Bacabal is $14^{\circ}$ east of the mean direction of $\Delta H$ vector during December 1990.

Chandra and Rastogi (1997) studied the deviations in $H, Y$ and $Z$ at Kodaikanal in India for a large number of geomagnetic storms during $1970-1991$. The ratio of $\Delta Y / \Delta H$ related to $\mathrm{SC}$ varied between -0.22 and -0.26 . Fukushima (1966) reported that most of the SC at Kakoika in Japan showed eastward declination changes and attributed this due to the declination $\left(6^{\circ} \mathrm{W}\right)$ and the geomagnetic meridian $\left(6^{\circ} \mathrm{E}\right.$ of geographic meridian) at Kakoika. The storm time variations of the magnetic field at an equatorial electrojet station is due to the combined effect of the ring current and of the ionospheric currents associated with the electric field transmitted from high latitudes. Thus the alignment of the $H$ vector due to the ring current could be different than that of the diurnal vector in $H$.

Fukushima (1966) had suggested that the impact of solar plasma on magnetosphere cause the magnetic field vectors of SC to align itself along the dipole meridian at the place. Rastogi et al. (2001) argued that the direction of the eastward component of the magnetic field due to ring current over a particular station should be given by the angle perpendicular to the dipole declination $(\psi)$. Dipole declinations are the geomagnetic field vector at magnetospheric region measured with respect to the geographic meridian. Undisturbed direction of $\Delta H$ at ground is given by the declination $\mathrm{D}$ with respect to the geographic north. Thus the deviation of declination due to the equatorial ring current would be given by the angle $\psi-D$. Rastogi et al. (2001) also showed that the changes in $\Delta Y, \Delta H$ 
during geomagnetic disturbances would be related by the relation

$$
\Delta Y / \Delta H=\sin (\psi-D) .
$$

This was confirmed by examining the deviations in $Y$ and $H$ at few mid-latitude stations. The declination values were positively or negatively correlated with Dst index depending upon the sign of the angle $(\psi-D)$. Later James et al. (2004) examined the deviations in $H$ and $Y$ fields for the IGY period with Dst index at low latitude stations around the world and showed a good correspondence between $\Delta Y / \Delta H$ and $\sin (\psi-D)$ for all the stations in the equatorial belt. For the IGY period ground declination was $5^{\circ} \mathrm{E}$ at Huancayo and $19.2^{\circ} \mathrm{W}$ at Tatuoca (geographic latitude of $48.5^{\circ} \mathrm{W}$ ). The dipole declinations at ring current altitude were $0.7^{\circ} \mathrm{E}$ for Huancayo and $4.2^{\circ} \mathrm{W}$ for Tatuoca. Looking at the contour plots of the angle $\psi$ shown by James et al. (2004) its value at Bacabal would be about $5^{\circ} \mathrm{W}$. Considering the ground declination of $20^{\circ} \mathrm{W}$, the value of $\sin (\psi-D)$ comes out to be 0.26 . Thus the ratio of $\Delta Y / \Delta H$ at Bacabal with a value of 0.28 for the event is very close to that obtained from the relation above.

Earlier studies in the East Brazilian region have shown that the direction of the $\Delta H$ vector changes with local time and season. The difference of few degrees in the alignment of the $\Delta H$ vector and the declination angle in the east Brazilian region was suggested to be due to the northward meridional current (Rastogi et al. 2010). As the polarity of IMF and the local time of SC play important role there is need for a detailed study in this region based on more case studies of the magnetic storm events.

\section{Acknowledgements}

The solar flare data were downloaded from SPIDR website. Thanks are due to Physical Research Laboratory, Ahmedabad for facilities provided for the analysis. RGR was the recipient of the senior scientist grant from Indian National Science Academy, New Delhi. Thanks are also to Rahul Shah for technical assistance during the investigations.

\section{References}

Araki T 1977 Global structure of geomagnetic sudden commencements; Planet Space Sci. 25 373-384.
Araki T, Keika K, Kamei T, Yang H and Alex S 2006 Nighttime enhancement of the amplitude of geomagnetic sudden commencements and its dependence on IMF Bz; Earth Planets Space 58 45-50.

Chandra H and Rastogi R G 1997 Geomagnetic storm effects on zonal and meridional equatorial electrojet currents; J. Geophys. Res. 102 11,611-11,617.

Chapman S 1919 The solar and lunar diurnal variation of earth's magnetic field; Phil. Trans. Roy. Soc. London A 218 118p.

Chapman S 1961 Regular motions in the ionosphere: Electric and magnetic relationships; Bull. Am. Meteorol. Soc. 42 85-100.

Clauer C R, Alexeev I I, Balenkaya E S and Baker J B 2001 Special features of the September 24-27 1998 storm during high solar wind dynamic pressure and northward interplanetary magnetic field; J. Geophys. Res. 106 25,695-25,771.

Forbush S E and Casaverde M 1961 The equatorial electrojet in Peru; Carnegie Inst Washington, Publication No. 620.

Fukushima N 1966 Declination changes of SC, its local time and seasonal dependence at Kakioka, Japan; J. Geomagn. Geoelectr. 18 99-112.

James M E, Rastogi R G and Winch D E 2004 Magnetic disturbance effect on geomagnetic field at low latitudes; Indian J. Radio Space Phys. 33 88-94.

McNish A G 1937 Terrestrial magnetic and ionospheric effects associated with light chromospheric eruptions; Terr. Magn. Atmos. Electr. 42 109-129.

Matsushita S and Maeda H 1965 On the geomagnetic solar quiet daily variation field during the IGY; J. Geophys. Res. 70 2535-2558.

Olson W P 1970 Contributions of nonionospheric currents to the quiet daily magnetic variations at earth's surface; J. Geophys. Res. 75 7244-7249.

Oshio M, Fukushima N and Nagata T 1967 Solar flare effects on geomagnetic field; Rep. Ionos. Space Res. Japan 21 $77-114$.

Parkinson W D 1971 An analysis of the geomagnetic diurnal variations during the International Geophysical Year; Gerlands Beitr. Geophysik Leipzig 80 199-232.

Riggoti A, Chanlaun F H, Trivedi N B and Padilha A L 1999 Characteristics of the equatorial electrojet determined from an array of magnetometers in N. N-E Brazil; Earth Planet Space 51 115-128.

Rastogi R G 2001a Solar flare effects in geomagnetic field at Indian stations - Part 1: Trivandrum, the center of equatorial electrojet; Indian J. Radio Space Phys. 30 1-6.

Rastogi R G 2001b Solar flare effects in geomagnetic field at Indian stations - Part II: Annamalainagar, near the edge of electrojet; Indian J. Radio Space Phys. 30 7-14.

Rastogi R G, Winch D E and James M E 2001 Longitudinal effects in geomagnetic disturbances at mid-latitudes; Earth Planet. Space 53 969-979.

Rastogi R G 2003 Effect of solar disturbances on the geomagnetic H, Y and Z fields in American equatorial electrojet stations 1. Solar flare effects; J. Indian Geophys. Union 7 43-51.

Rastogi R G and Trivedi N B 2009 Asymmetries in the equatorial electrojet around N-E Brazil sector; Ann. Geophys. 27 1233-1249. 
Rastogi R G, Chandra H and Yumoto K 2010 Equatorial electrojet in East Brazil; J. Earth Syst. Sci. 119 497-505.

Rastogi R G, Chandra H, Rahul Shah,Trivedi N B and Fontes S L 2013 A comparison of equatorial electrojet in Peru and East Brazil; Open Atmos. Sci. J. 7 29-36.

Russel C T, Ginskey M and Patrinec S M 1994 Sudden impulses at low latitude stations: Steady state response

Corresponding editor: K KRISHNAmoorthy for northward interplanetary magnetic field; J. Geophys. Res. 99 253-261.

Sarabhai V and Nair K N 1971 Morphology of the geomagnetic field variations and a study of the interplanetary magnetic field fluctuations in relation to the daily variation of the geomagnetic field at low latitudes; Cosmic Electrodyn. 2 3-21. 